\title{
Graus de resistência à brusone e produtividade de cultivares melhoradas de arroz de terras altas(1)
}

\begin{abstract}
Anne Sitarama Prabhu(2) e Marta Cristina Filippi ${ }^{(2)}$
Resumo - O objetivo deste trabalho foi estudar o nível de resistência à brusone nas folhas e panículas e seu efeito sobre a produtividade de 12 cultivares de arroz, em experimento de campo, durante três anos consecutivos. $\mathrm{O}$ grau de resistência das cultivares à brusone nas folhas e panículas foi determinado utilizando-se o critério de área sob curva de progresso e severidade de brusone nas panículas dez dias antes de colheita, respectivamente. As cultivares Progresso, Cuiabana, Caiapó, Carajás e Araguaia, em ordem decrescente, foram as mais resistentes à brusone nas folhas. As cultivares Carajás e Progresso apresentaram severidades da brusone, nas panículas, menores do que as demais cultivares em dois anos. A produtividade das cultivares nos três anos de avaliações, que variou de $83 \mathrm{~kg} / \mathrm{ha}$ na IAC 201 a $3.617 \mathrm{~kg} /$ ha na Rio Paraguai, é explicada principalmente pela severidade da brusone nas panículas, já que as correlações foram negativas e significativas. As raças de Pyricularia grisea, IB-9, IB-41, IB-13 e IC-27, provenientes de 13 cultivares, apresentaram interações diferenciais. Os resultados permitiram concluir que o grau de resistência de algumas cultivares é inadequado e necessita de outras medidas de controle.
\end{abstract}

Termos para indexação: Oryza sativa, Pyricularia grisea, resistência a doenças, patogenicidade

\section{Degree of blast resistance and grain yield of improved upland rice cultivars}

Abstract - The aim of this work was to study the levels of leaf and panicle blast resistance and their effect on grain yield of 12 rice cultivars, in a field experiment, during consecutive three years. The degree of leaf blast and panicle blast resistance was determined by the assessment criteria of area under disease progress curve and disease severity ten days before the harvest, respectively. The cultivars Progresso, Cuiabana, Caiapó, Carajás and Araguaia were superior in descending order for leaf blast resistance. For panicle blast, Carajás and Progresso, exhibited lower disease severities than the rest of the cultivars in the first two years. The grain yields during three years ranged from $83 \mathrm{~kg} / \mathrm{ha}$ for IAC 201 to $3,617 \mathrm{~kg} / \mathrm{ha}$ for Rio Paraguai, and the variation was explained by blast severity, in the panicles, as the correlations were negative. The races IB-9, IB-41, IB-13 and IC-27 of Pyricularia grisea obtained from 13 cultivars showed differential interaction. These results permitted to conclude that the degree of resistance of some of the cultivars was inadequate and other measures of disease control are necessary.

Index terms: Oryza sativa, Pyricularia grisea, disease resistance, pathogenicity.

\section{Introdução}

O arroz de terras altas, embora responda por $58,7 \%$ da produção total de 10,9 milhões de toneladas no Brasil, tem uma baixa produtividade média de 1,7 t/ha, de acordo com Levantamento Sistemático

\footnotetext{
(1) Aceito para publicação em 8 de novembro de 2000 .

(2) Embrapa-Centro Nacional de Pesquisa de Arroz e Feijão (CNPAF), Caixa Postal 179, CEP 75375-000, Santo An tônio de Goiás, GO. E-mail: prabhu@enpaf.embrapa.br, cfilippi@ppserver.tamu.edu
}

da Produção Agrícola (1999). O Brasil é o maior produtor de arroz no Mercosul, com 10,6 milhões de toneladas, correspondendo a $84,8 \%$ do total de 12,5 milhões de toneladas produzidas, considerando-se as médias durante 1993 a 1995. Nesse período, o Brasil foi o maior importador mundial de arroz, com importações estimadas em 1,2 milhão de toneladas para atender o consumo interno (Waquil, 1997).

A brusone, causada por Pyricularia grisea (Cooke) Sacc., constitui um dos principais fatores que afetam a produtividade das cultivares de terras altas. A resistência da cultivar é o principal componente no manejo integrado da brusone. 
Diversas cultivares de terras altas, com diferentes graus de resistência à brusone, foram desenvolvidas ao longo dos anos, pela Embrapa, juntamente com as empresas estaduais de pesquisa no País. O grau de resistência é comumente expresso pela severidade da doença na planta ou no tecido afetado e pela área sob curva de progresso (Parlevliet, 1977). A brusone nas folhas durante a fase vegetativa causa redução na altura da planta, no número de perfilhos, no número de grãos por panícula e no peso de grãos (Prabhu et al., 1986), além dos efeitos indiretos na produtividade causada pelas reduções na taxa de fotossíntese e respiração (Sun et al., 1986; Bastiaans et al., 1994). Os efeitos diretos causados por brusone nas panículas incluem redução na produtividade, peso de grãos, porcentagem de grãos formados, número de grãos por panícula e índice de colheita (Prabhu et al., 1986; Pinnschmidt et al., 1994). Estudos anteriores com seis cultivares sob dois níveis de $\mathrm{N}$ mostraram que as cultivares Guarani, Centro América, Rio Paranaíba e Cuiabana apresentaram progresso lento da brusone nas folhas, e contribuíram para a redução da brusone, variando de $19 \%$ a $56 \%$, comparado com as cultivares IAC 165 e IAC 47 (Prabhu et al., 1996). As informações sobre as diferenças entre as cultivares melhoradas, em relação ao grau de resistência e seu efeito na produtividade, fornecem bases para o manejo da brusone, integrando outras medidas de controle. O conhecimento das raças de $P$. grisea que afetam as cultivares no campo e do seu padrão de virulência é importante para a incorporação da resistência nestas cultivares.

Este trabalho objetivou estudar o nível de resistência à brusone nas folhas e panículas, e seu efeito sobre a produtividade de 12 cultivares de arroz, e identificar as raças que afetam as cultivares nas condições naturais de infecção no campo.

\section{Material e Métodos}

Foi realizado um experimento de campo, em um Latossolo Vermelho-Amarelo distrófico, durante três anos agrícolas 1994/95, 1995/96 e 1996/97, respectivamente, nos campos experimentais da Embrapa-Centro Nacional de Pesquisa de Arroz e Feijão, no Município de Santo Antônio de Goiás, GO. O solo foi adubado com $250 \mathrm{~kg} / \mathrm{ha}$ da fórmula 4-30-16 + Zn no primeiro ano, e $400 \mathrm{~kg} / \mathrm{ha}$ da fórmula 4-30-10 no segundo e terceiro ano, além de
$125 \mathrm{~kg} / \mathrm{ha}$ de sulfato de amônio e $20 \mathrm{~kg} /$ ha de sulfato de zinco, na ocasião do plantio dos experimentos. A adubação de cobertura foi feita 50 dias após a semeadura, com $125 \mathrm{~kg} / \mathrm{ha}$ de sulfato de amônio. O delineamento experimental utilizado foi o de blocos ao acaso, com três repetições, e composto de parcelas com $6,4 \mathrm{~m}^{2}$, que consistiram de quatro fileiras de 4,0 m de comprimento, com espaços de $0,4 \mathrm{~m}$. A densidade de semeadura foi de 70 sementes por metro linear. Foi estabelecida, 30 dias antes do plantio do experimento, uma bordadura infestante de três fileiras nas duas cabeceiras de cada bloco, com uma mistura de cultivares suscetíveis (IAC 47, IAC 25, IAC 165, IRAT 112) em proporções iguais. O experimento foi instalado em 2, 23 e 7 de dezembro de 1994, 1995 e 1996, respectivamente, com as cultivares Araguaia, Caiapó, Carajás, Cuiabana, Douradão, Guarani, IAC 201, Progresso, Rio Paranaíba, Rio Paraguai, Rio Verde e Tangará. O controle de ervas daninhas foi feito por meio de capinas, sempre que necessário. O experimento foi protegido contra o ataque de pragas, pela aplicação de inseticidas recomendados para a cultura.

A porcentagem de área foliar afetada pela brusone nas folhas foi determinada em quatro ou cinco folhas completamente abertas, dos dez perfilhos principais de cada planta, em duas linhas centrais da parcela. Utilizouse uma escala de 10 graus $(0,0,5,1,2,4,8,16,32,64$ e $82 \%$ de área foliar afetada), de acordo com Notteghem (1981). As observações foram feitas em intervalos de três ou quatro dias, iniciando-se 30 dias após o plantio no primeiro e segundo ano do experimento, e a severidade de brusone nas folhas foi avaliada somente uma vez, 39 dias após o plantio, no terceiro ano do experimento.

A severidade da brusone nas panículas foi avaliada em 50 panículas, em duas linhas centrais, dez dias antes da colheita, com uma escala de seis graus $(0,5,25,50,75 \mathrm{e}$ $100 \%$ de espiguetas/panículas infectadas). A determinação da produção de grãos $(\mathrm{kg} / \mathrm{ha})$ baseou-se na colheita das duas linhas centrais da parcela. A produção foi ajustada para $13 \%$ de umidade antes e depois de abanar.

Foram efetuadas as análises individuais e conjuntas ( 2 ou 3 anos) das variáveis medidas, assumindo-se sempre o modelo fixo. A área sob a curva de progresso (ASCP) da brusone nas folhas foi calculada em cada cultivar, de acordo com Shaner \& Finney (1977). Os valores da ASCP foram transformados para log, procurando-se uma melhor homogeneidade de variância. A análise da severidade de brusone nas folhas e panículas em porcentagem foi realizada após a transformação dos dados em arco seno $\sqrt{\%}$. Estudouse também a relação entre a brusone nas folhas e panículas e seu efeito na produtividade, pela análise de correlação e regressão. 
Isolados monospóricos de $P$. grisea provenientes de lesões esporulativas coletadas nas folhas das doze cultivares, nos experimentos de campo, foram estabelecidos e conservados em papel de filtro esterilizado. A identificação das raças fisiológicas e do padrão de virulência foi feita por meio de inoculações artificiais, em casa de vegetação, utilizando 12 isolados, um de cada cultivar, além de um isolado proveniente da cultivar IAC 47. Os plantios de 32 genótipos, incluindo 12 cultivares de terras altas (Araguaia, Caiapó, Carajás, Cuiabana, Douradão, Guarani, IAC 201, Progresso, Rio Paranaíba, Rio Paraguai, Rio Verde e Tangará), oito diferenciadoras internacionais utilizadas para diferenciação de raças fisiológicas (Dular, Kanto 51, NP125, Raminad Str 3, Usen, Zenith, Coloro, Sha-Tia-Tsão), cinco linhas isogênicas de CO 39 (C 101 LAC, C101A 51, C104 PKT, C101 PKT, C101-TTP-4L-23), IAC-47, Canastra, Maravilha, Primavera, testemunha para resistência parcial (Moroberekan), e testemunha suscetível (Raminad Str 3-CIAT), foram feitos em bandejas contendo solo adubado com NPK. O plantio dos genótipos foi feito em duas bandejas, com $16 \mathrm{em}$ cada bandeja, em linhas de $5 \mathrm{~cm}$ As inoculações foram feitas com suspensão de conídios $\left(3 \times 10^{5}\right)$ nas plantas com 21 dias de idade, separadamente, com 13 isolados. As inoculações foram repetidas duas vezes, e analisaram-se as reações consistentes. As avaliações de reação da brusone nas folhas foram realizadas com a utilização de uma escala padronizada de 0-9 (International Rice Research Institute, 1988). Foram consideradas como não-compatíveis ou resistentes, as reações 0-3, e como compatíveis ou suscetíveis, as reações 4-9. A virulência dos isolados foi determinada com uma proporção variando de 0 a 1 (número de genótipos com reação compatível dividido pelo número total de genótipos submetidos a inoculação).

\section{Resultados e Discussão}

A análise de variância dos dados de cada ano mostrou que o efeito de cultivar foi altamente significativo na área sob a curva de progresso (ASCP), em relação à brusone nas folhas, à severidade da brusone nas panículas, e à produtividade de grãos.

A análise conjunta dos experimentos do Ano $1 \mathrm{e}$ do Ano 2 indicou que a cultivar e a interação cultivar $\mathrm{x}$ ano foram altamente significativas na ASCP. Os valores da ASCP das cultivares Progresso, Caiapó, Carajás e Araguaia foram menores e diferiram significativamente da Rio Paranaíba e Tangará, no primeiro ano (Figura 1). Por outro lado, no segundo ano, as cultivares Caiapó, Carajás, Cuiabana e Araguaia apresentaram valores de ASCP menores quando comparadas com IAC 201. A análise conjunta de valores de ASCP mostrou que as cultivares Araguaia, Carajás, Caiapó, Cuiabana e Progresso foram significativamente superiores à Tangará, IAC 201, Douradão, Guarani, Rio Paranaíba, Rio Paraguai e Rio Verde. As diferenças entre a ordem de classificação das cultivares nos dois anos, quanto ao grau de resistência à brusone nas folhas, podem ser atribuídas a uma possível variação na freqüência das raças.

As interações entre cultivar e ano na análise conjunta de três anos, quanto a severidade da brusone nas panículas e quanto à produtividade foram significativas (Tabela 1). A severidade da brusone nas panículas entre as cultivares variou de $1,5 \%$ a $58,7 \% ; 1,5 \%$ a $76,7 \%$ e $4,0 \%$ a $23,0 \%$, no primeiro, segundo e terceiro ano, respectivamente. A cultivar IAC 201 apresentou altas severidades nos dois primeiros anos. O comportamento das cultivares quanto à severidade da brusone nas panículas não foi coincidente nos diferentes anos.

A produtividade da cultivar IAC 201 foi altamente afetada pela brusone nas panículas, e significativamente menor $(672 \mathrm{~kg} / \mathrm{ha})$, quando comparada à produtividade máxima da Rio Paraguai, que foi de

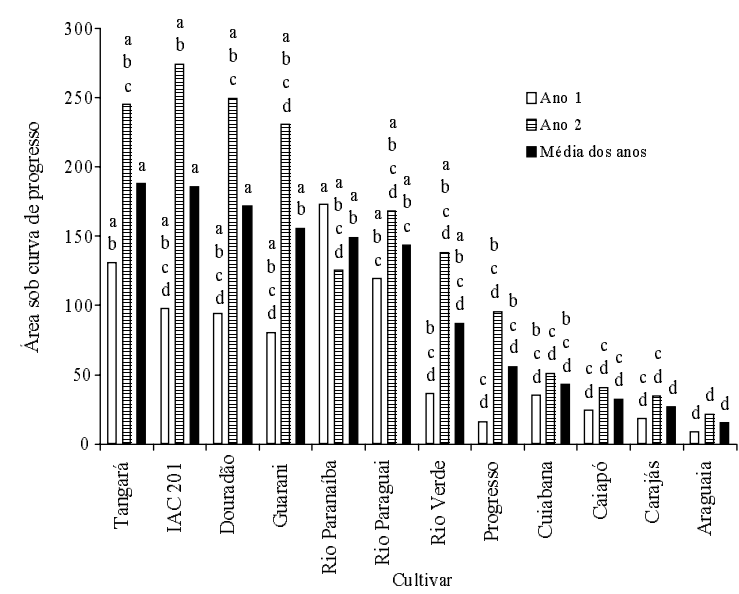

Figura 1. Área sob a curva de progresso (ASCP) de brusone nas folhas em 12 cultivares de arroz de terras altas nas condições de infecção natural no campo, Santo Antônio de Goiás, GO. Médias com a mesma letra nas barras não diferem entre si pelo teste de Tukey $(\mathrm{P} \geq 0,05)$. 
$1.865 \mathrm{~kg} / \mathrm{ha}$ no primeiro ano. No segundo ano, a produtividade variou entre $83 \mathrm{~kg} / \mathrm{ha}$ (IAC 201) e $3.617 \mathrm{~kg} / \mathrm{ha}$ (Rio Paraguai). No terceiro ano, foram obtidas produtividades de $366 \mathrm{~kg} / \mathrm{ha}$ da IAC $201 \mathrm{e}$ $1.834 \mathrm{~kg} /$ ha da Guarani.

As correlações entre severidade da brusone nas folhas (SBF) e ASCP foram positivas e altamente significativas no Ano 1 e Ano 2 (Tabela 2). Em todos os três anos, somente a severidade da brusone nas panículas explicou a variação na produtividade, pois as correlações entre severidade da brusone nas panículas e a produtividade de grãos foram negativas e significativas. A severidade da brusone nas folhas não afetou a produtividade, pois esta não atingiu níveis prejudiciais, o que foi evidenciado pelas correlações não-significativas. Além da brusone nas folhas e panículas, as diferenças nos ciclos das cultivares e condições climáticas durante a formação de grãos contribuíram para o diferente comportamento das cultivares quanto à produtividade.

Houve interações diferenciais entre os isolados de $P$. grisea e cultivares (Tabela 3 ). O isolado proveniente da cultivar Carajás não foi virulento para a cultivar Caiapó, e vice-versa. O isolado da cultivar Cuiabana foi altamente específico e não foi virulento em nenhuma das 12 cultivares, inclusive na IAC 47, utilizada como testemunha. Os isolados da Carajás e Guarani foram virulentos na cultivar Araguaia, enquanto o isolado de Araguaia foi avirulento na Carajás e virulento na Guarani. Filippi et al. (1999) também observaram compatibilidade diferencial entre cultivares e isolados de arroz irrigado.

Tabela 1. Severidade da brusone nas panículas (SBP, \%) e produtividade (PROD, $\mathrm{kg} / \mathrm{ha}$ ) em 12 cultivares de arroz de terras altas, durante três anos. Santo Antônio de Goiás, GO (1994/96) ${ }^{(1)}$.

\begin{tabular}{|c|c|c|c|c|c|c|}
\hline \multirow[t]{2}{*}{ Cultivar } & \multicolumn{2}{|c|}{ Ano 1} & \multicolumn{2}{|c|}{ Ano 2} & \multicolumn{2}{|c|}{ Ano 3} \\
\hline & SBP & PROD & SBP & PROD & SBP & PROD \\
\hline IAC 201 & $58,7 \mathrm{a}$ & $672 d$ & $76,7 a$ & $83 e$ & $23,0 a$ & $366 \mathrm{~d}$ \\
\hline Araguaia & $19,5 b$ & $1.400 \mathrm{abc}$ & $1,5 \mathrm{~d}$ & $3.175 \mathrm{ab}$ & $13,5 \mathrm{ab}$ & $1.243 \mathrm{abc}$ \\
\hline Rio Paranaíba & $13,8 \mathrm{bc}$ & $1.810 \mathrm{a}$ & $10,7 \mathrm{~d}$ & $2.990 \mathrm{abc}$ & $12,0 \mathrm{ab}$ & $1.278 \mathrm{abc}$ \\
\hline Cuiabana & $12,6 b c$ & $1.545 \mathrm{abc}$ & $2,8 \mathrm{~d}$ & $3.542 \mathrm{a}$ & $16,6 a b$ & $643 \mathrm{~cd}$ \\
\hline Tangará & $12,4 b c$ & $1.355 \mathrm{abc}$ & $51,2 \mathrm{ab}$ & $1.401 \mathrm{bcde}$ & $10,3 \mathrm{ab}$ & $1.099 \mathrm{bc}$ \\
\hline Rio Paraguai & $12,1 \mathrm{bc}$ & $1.865 \mathrm{a}$ & $9,0 \mathrm{~d}$ & $3.617 \mathrm{a}$ & $21,3 \mathrm{ab}$ & $1.001 \mathrm{bcd}$ \\
\hline Douradão & $11,5 b c$ & $1.595 \mathrm{ab}$ & $41,6 \mathrm{~d}$ & $1.203 \mathrm{cde}$ & $9,3 \mathrm{ab}$ & $1.309 \mathrm{abc}$ \\
\hline Caiapó & $10,2 b c$ & $1.527 \mathrm{abc}$ & $6,3 d$ & $2.858 \mathrm{abc}$ & $5,9 \mathrm{ab}$ & $910 \mathrm{~cd}$ \\
\hline Rio Verde & $10,0 \mathrm{bc}$ & $1.735 \mathrm{ab}$ & $7,5 \mathrm{~d}$ & $2.646 \mathrm{abcd}$ & $17,5 \mathrm{ab}$ & $1.123 b c$ \\
\hline Guarani & $5,5 \mathrm{~cd}$ & $1.435 \mathrm{abc}$ & $18,7 \mathrm{~d}$ & $925 \mathrm{de}$ & $4,0 \mathrm{~b}$ & $1.834 \mathrm{a}$ \\
\hline Progresso & $4,8 \mathrm{~cd}$ & $1.125 \mathrm{bcd}$ & $6,3 d$ & $2.727 \mathrm{abcd}$ & $18,9 \mathrm{ab}$ & $834 \mathrm{~cd}$ \\
\hline Carajás & $1,5 \mathrm{~d}$ & $943 \mathrm{~cd}$ & $12,0 \mathrm{~d}$ & $1.503 \mathrm{abcde}$ & $13,9 \mathrm{ab}$ & $1.643 \mathrm{ab}$ \\
\hline
\end{tabular}

Tabela 2. Coeficientes de correlações (r) entre os parâmetros da brusone e produtividade $(1994 / 96)^{(1)}$.

\begin{tabular}{|c|c|c|c|c|c|}
\hline \multirow[t]{2}{*}{ Parâmetro ${ }^{(2)}$} & \multirow[t]{2}{*}{ Ano } & \multicolumn{2}{|c|}{ Brusone } & \multicolumn{2}{|c|}{ Produção ${ }^{(3)}$} \\
\hline & & $\mathrm{ASCP}$ & SBP & PROD 1 & PROD 2 \\
\hline \multirow[t]{3}{*}{ SBF } & 1 & $0,623 * *$ & $0,047^{\mathrm{ns}}$ & $0,228^{\text {ns }}$ & $0,222^{\text {ns }}$ \\
\hline & 2 & $0,885^{* *}$ & $0,290^{\mathrm{ns}}$ & $-0,280^{\mathrm{ns}}$ & $-0,271^{\mathrm{ns}}$ \\
\hline & 3 & & $0,259^{\mathrm{ns}}$ & $-0,131^{\mathrm{ns}}$ & $-0,146^{\mathrm{ns}}$ \\
\hline \multirow[t]{3}{*}{ ASCP } & 1 & & $0,237^{\mathrm{ns}}$ & $0,161^{\mathrm{ns}}$ & $0,152^{\mathrm{ns}}$ \\
\hline & 2 & & $0,502 * *$ & $-0,404 * *$ & $-0,389 * *$ \\
\hline & 3 & & - & - & - \\
\hline \multirow[t]{3}{*}{ SBP } & 1 & & & $-0,405 * *$ & $-0,414 * *$ \\
\hline & 2 & & & $-0,404 * *$ & $-0,389 * *$ \\
\hline & 3 & & & $-0,457 * *$ & $-0,473 * *$ \\
\hline
\end{tabular}

(1)Número de observações na análise:36. (2)SBF, ASCP e SBP: severidade de brusone nas folhas, área sob curva de progresso e severidade de brusone nas panículas (\%), respectivamente. ${ }^{(3)}$ PROD 1 e PROD 2: produção $(\mathrm{kg} / \mathrm{ha})$ antes e depois de abanar, respectivamente. ${ }^{\text {ns }}$ Não-significativo. ${ }^{* *}$ Significativo a $1 \%$ de probabilidade 
A freqüência de virulência dos isolados testados variou de 0,3 a 0,8 . Os isolados provenientes da Guarani foram mais virulentos, seguidos por isolados de IAC 201, IAC 47 e Tangará. Esses resultados demonstraram que o comportamento das cultivares, em diferentes anos, quanto ao grau de resistência, possivelmente depende da freqüência de ocorrência de isolados virulentos no campo.

Houve raças de $P$. grisea compatíveis em todas as 12 cultivares de terras altas, nos campos experimentais. $\mathrm{O}$ número de isolados compatíveis em 13 cultivares, inclusive na cultivar tradicional IAC 47,

Tabela 3. Reação de genótipos de arroz aos isolados de Pyricularia grisea provenientes de cultivares de arroz de terras $\operatorname{altas}(1994 / 96)^{(1)}$.

\begin{tabular}{|c|c|c|c|c|c|c|c|c|c|c|c|c|c|c|}
\hline \multirow[t]{3}{*}{ Genótipo } & \multicolumn{14}{|c|}{ Isolado $^{(2)}$} \\
\hline & ar & $\mathrm{cp}$ & $\mathrm{cj}$ & $\mathrm{cu}$ & do & gu & 47 & 201 & $\mathrm{pr}$ & $\mathrm{rb}$ & $\mathrm{rp}$ & rv & ta & $\mathrm{N}^{(3)}$ \\
\hline & 646 & 874 & 863 & 632 & 618 & 912 & 722 & 733 & 963 & 292 & 671 & 277 & 544 & \\
\hline \multicolumn{15}{|l|}{ Cultivares } \\
\hline Araguaia (ar) & 2 & 2 & 9 & 1 & 4 & 9 & 2 & 3 & 0 & 0 & 0 & 0 & 3 & 3 \\
\hline Caiapó (cp) & 4 & 9 & 0 & 3 & 0 & 0 & 0 & 0 & 0 & 0 & 4 & 0 & 0 & 3 \\
\hline Carajás (cj) & 0 & 0 & 7 & 0 & 0 & 0 & 1 & 0 & 0 & 0 & 0 & 0 & 0 & 1 \\
\hline Cuiabana (cu) & 9 & 9 & 0 & 9 & 1 & 0 & 0 & 0 & 0 & 0 & 0 & 0 & 5 & 4 \\
\hline Douradão (do) & 0 & 2 & 3 & 0 & 4 & 7 & 7 & 7 & 0 & 4 & 0 & 7 & 9 & 7 \\
\hline Guarani (gu) & 9 & 9 & 9 & 0 & 5 & 9 & 9 & 7 & 0 & 7 & 0 & 3 & 7 & 9 \\
\hline $\mathrm{IAC}-47(47)$ & 9 & 9 & 9 & 0 & 9 & 9 & 9 & 9 & 5 & 7 & 5 & 0 & 9 & 11 \\
\hline IAC-201(201) & 9 & 9 & 9 & 0 & 7 & 7 & 9 & 9 & 5 & 9 & 0 & 4 & 9 & 11 \\
\hline Progresso (pr) & 1 & 1 & 0 & 1 & 3 & 1 & 1 & 2 & 4 & 0 & 0 & 0 & 0 & 1 \\
\hline R. Paranaíba (rb) & 9 & 3 & 9 & 0 & 5 & 9 & 9 & 9 & 0 & 7 & 4 & 0 & 5 & 9 \\
\hline R. Paraguai (rp) & 3 & 2 & 3 & 1 & 3 & 4 & 9 & 7 & 0 & 0 & 4 & 2 & 5 & 5 \\
\hline Rio Verde (rv) & 2 & 2 & 3 & 1 & 0 & 7 & 3 & 5 & 3 & 2 & 5 & 1 & 5 & 4 \\
\hline Tangará (ta) & 9 & 7 & 4 & 0 & 3 & 0 & 0 & 3 & 3 & 0 & 0 & 0 & 0 & 3 \\
\hline \multicolumn{15}{|c|}{ Diferenciadoras internacionais } \\
\hline Dular & 0 & 0 & 0 & 0 & 0 & 0 & 0 & 0 & 0 & 0 & 0 & 0 & 0 & 0 \\
\hline Kanto 51 & 7 & 9 & 1 & 9 & 7 & 9 & 9 & 9 & 5 & 7 & 5 & 5 & 9 & 12 \\
\hline NP 125 & 0 & 9 & 4 & 4 & 3 & 7 & 9 & 9 & 0 & 0 & 4 & 0 & 9 & 8 \\
\hline Raminad Str 3 & 0 & 0 & 0 & 0 & 0 & 0 & 0 & 0 & 0 & 0 & 0 & 0 & 0 & 0 \\
\hline Usen & 7 & 9 & 9 & 0 & 9 & 9 & 9 & 9 & 7 & 9 & 7 & 7 & 9 & 12 \\
\hline Zenith & 7 & 9 & 9 & 0 & 9 & 9 & 4 & 9 & 5 & 9 & 9 & 7 & 9 & 12 \\
\hline Calor & 4 & 9 & 9 & 0 & 9 & 9 & 4 & 9 & 4 & 9 & 7 & 7 & 9 & 12 \\
\hline Sha-tia-tsao & 9 & 9 & 9 & 9 & 9 & 9 & 9 & 9 & 9 & 9 & 9 & 7 & 9 & 13 \\
\hline \multicolumn{15}{|l|}{ Linhas isogênicas $^{(4)}$} \\
\hline C101 LAC & 0 & 9 & 1 & 5 & 0 & 4 & 4 & 3 & 2 & 0 & 0 & 0 & 4 & 5 \\
\hline C101 A51 & 0 & 4 & 4 & 4 & 0 & 4 & 4 & 4 & 0 & 0 & 0 & 0 & 4 & 7 \\
\hline C104 PKT & 5 & 9 & 9 & 9 & 7 & 9 & 9 & 9 & 5 & 7 & 5 & 9 & 9 & 13 \\
\hline C101 PKT & 5 & 9 & 9 & 9 & 7 & 9 & 9 & 9 & 5 & 7 & 5 & 9 & 9 & 13 \\
\hline C105 TTP4L23 & 0 & 4 & 9 & 3 & 0 & 4 & 4 & 7 & 0 & 2 & 0 & 0 & 5 & 6 \\
\hline \multicolumn{15}{|l|}{ Padrões ${ }^{(5)}$} \\
\hline IRAT 13 & 0 & 3 & 3 & 0 & 4 & 7 & 5 & 5 & 0 & 3 & 0 & 4 & 4 & 6 \\
\hline Moroberekan & 0 & 1 & 4 & 1 & 5 & 9 & 9 & 5 & 0 & 4 & 4 & 4 & 4 & 9 \\
\hline \multicolumn{15}{|l|}{ Novas cultivares } \\
\hline Canastra & 0 & 7 & 4 & 3 & 2 & 9 & 4 & 5 & 0 & 1 & 0 & 3 & 3 & 5 \\
\hline Maravilha & 0 & 4 & 3 & 4 & 2 & 9 & 4 & 3 & 0 & 0 & 0 & 3 & 4 & 5 \\
\hline Primavera & 0 & 0 & 0 & 9 & 0 & 4 & 1 & 3 & 0 & 0 & 0 & 0 & 1 & 2 \\
\hline C. suscetível ${ }^{(6)}$ & 7 & 4 & 9 & 5 & 4 & 9 & 9 & 7 & 7 & 9 & 7 & 9 & 9 & 13 \\
\hline $\operatorname{Raça}^{(7)}$ & IB41 & IB9 & IB13 & $\mathrm{IC} 27$ & IB41 & IB9 & IB9 & IB9 & IB41 & IB41 & IB9 & IB41 & IB9 & \\
\hline Virulência $^{(8)}$ & 0,5 & 0,6 & 0,6 & 0,3 & 0,4 & 0,8 & 0,7 & 0,7 & 0,3 & 0,4 & 0,5 & 0,4 & 0,7 & \\
\hline
\end{tabular}

${ }^{(1)}$ As reações dos genótipos não-compatíveis ( 0 a 3 ) e compatíveis (4 a 9) correspondem a avirulência e virulência dos isolados, respectivamente. (2) Os isolados foram obtidos de lesões esporulantes nas folhas de 13 cultivares comerciais (1994/96) (3)Número total de isolados compatíveis ${ }^{(4)}$ Linhas isogênicas com genes conhecidos. ${ }^{(5)}$ Padrões de resistência parcial. ${ }^{(6)}$ Diferenciadora Raminad utilizada no CIAT como testemunha suscetível. ${ }^{(7)}$ As raças fisiológicas foram identificadas com base em oito cultivares diferenciadoras internacionais. ${ }^{\left({ }^{8}\right)} \mathrm{O}$ índice de virulência baseou-se no número total de reações compatíveis em relação aos 32 genótipos testados 
variou de 1 a 13 . Os isolados pertencentes às raças IB-9 e IB-41 ainda podem ser diferenciados com base na virulência das 13 cultivares comerciais de terras altas. Por exemplo, a raça IB-9, proveniente da Caiapó e Guarani, apresentou reações diferenciais nas cultivares Caiapó e Rio Verde, o que indica a importância da utilização de cultivares comerciais como diferenciadoras locais (Tabela 3). Estas duas raças ocorrem em maior freqüência nas cultivares de arroz de terras altas (Filippi \& Prabhu, 1996). A raça IC-27, coletada da 'Cuiabana', embora tenha apresentado menor índice de virulência, foi altamente agressiva na nova cultivar, Primavera. As cultivares Carajás, Progresso e Rio verde apresentaram o número menor de isolados compatíveis. Essas cultivares mostraram maior grau de resistência, comparadas às cultivares IAC 201, Rio Paranaíba e Guarani, que mostraram maior freqüência de compatibilidade aos 13 isolados.

Alguns isolados, como 646,277 e 544 , provenientes de Araguaia, Rio Verde e Tangará, respectivamente, não foram compatíveis com as cultivares de origem, e compatíveis em outras cultivares (Tabela 3). Resultados semelhantes foram obtidos nos estudos realizados com isolados coletados das cultivares resistentes como Chogoku 31 e St 1, no Japão, e isolados da Tetep nas Filipinas (Ou, 1980) e da Colômbia (Correa-Victoria \& Zeigler, 1993). Quando isolados monospóricos provenientes da Tetep e Carreon foram inoculados nas diferenciadoras das Filipinas, eles apresentaram diferentes padrões de virulência, e a maioria não infectou Tetep e Carreon. Este fenômeno foi explicado pela produção de conídios de diferentes padrões de virulência, quando multiplicado em meio de cultura e pelo amplo espectro de resistência das cultivares ( $\mathrm{Ou}$ et al., 1971).

O isolado da Caiapó foi altamente agressivo na linha isogênica $\mathrm{C} 101 \mathrm{LAC}$, e poderá ser utilizado nos estudos de incorporação de gene de resistência Pi-1. As raças compatíveis com os genes de resistência nas novas cultivares de terras altas, como Canastra, Maravilha e Primavera, são preexistentes no campo. Estudos mais detalhados visando a conhecimentos em relação à diversidade do patógeno nos locais de teste de populações segregantes e à identificação de isolados específicos das cultivares comerciais são necessários para o melhoramento genético quanto à resistência às raças mais freqüentes. $\mathrm{O}$ grau de resistência das cultivares comerciais atualmente plantadas é inadequado, e necessita de outras medidas de controle.

\section{Conclusões}

1. A brusone nas panículas contribui significativamente para a variação na produtividade em diferentes cultivares.

2. As cultivares melhoradas de terras altas diferem em níveis de infecção de brusone nas folhas e nas panículas.

3. A interação diferencial observada entre as cultivares comerciais e isolados de Pyricularia grisea demonstram a importância da incorporação de genes de resistência nas novas cultivares contra raças específicas mais freqüentes.

\section{Agradecimentos}

Ao Dr. Francisco José P. Zimmermann, da Embrapa-Centro Nacional de Pesquisa de Arroz e Feijão, pela ajuda na análise estatística dos dados experimentais.

\section{Referências}

BASTIAANS, L.; RABBINGE, R.; ZADOKS, J. C. Understanding and modeling leaf blast effects on crop physiology and yield. In: ZEIGLER, R. S.; LEONG, S. A.; TENG, P. S. (Ed.). Rice blast disease. Wallingford: CAB, 1994. p. $357-380$

CORREA-VICTORIA, F. J.; ZEIGLER, R. S. Pathogenic variability in Pyricularia grisea at a rice blast "hot-spot" breeding site in Eastern Colombia. Plant Disease, St. Paul, v. 77, n. 10, p. 1029-1035, 1993.

FILIPPI, M. C.; PRABHU, A. S. Inheritance of blast resistance in rice to two Pyricularia grisea races, $\mathrm{IB}-1$ and IB-9. Brazilian Journal of Genetics, Ribeirão Preto, v. 19, n. 4, p. 599-604, 1996.

FILIPPI, M. C.; PRABHU, A. S.; LEVY, E. M. Differential compatibility of Pyricularia grisea isolates with some Brazilian irrigated rice cultivars. Fitopatologia Brasileira, Brasília, v. 24, n. 3, p. 447-450, 1999. 
INTERNATIONAL RICE RESEARCH INSTITUTE (Los Baños, Filipinas). Standard evaluation system for rice. Manila, 1988. $54 \mathrm{p}$

LEVANTAMENTO SISTEMÁTICO DA PRODUÇÃO AGRÍCOLA. Rio de Janeiro: IBGE, v. 11, n. 11, dez. 1999.

NOTTEGHEM, J. L. Cooperative experiment on horizontal resistance to rice blast. In: INTERNATIONAL RICE RESEARCH INSTITUTE (Los Baños, Filipinas). Blast and upland rice: report and recommendations from the meeting for international collaboration in upland rice improvement. Los Baños, 1981. p. 43-51.

OU, S. H. Pathogen variability and host resistance in rice blast disease. Annual Review of Phytopathology, Palo Alto, v. 18, p. 167-187, 1980.

OU, S. H.; NUQUE, F. L.; EBRON, T. T.; AWODERU, V. A. A type of stable resistance to blast disease of rice. Phytopathology, St. Paul, v. 61, n. 6, p. 703-706, June 1971.

PARLEVLIET, J. E. Components of resistance that reduce the rate of epidemic development. Annual Review of Phytopathology, Palo Alto, v. 17, p. 203-224, 1977.

PINNSCHMIDT, H. O.; TENG, P. S.; YONG, L. Methodology for quantifying rice yield effects of blast.
In: ZEIGLER, R. S.; LEONG, S. A.; TENG, P. S. (Ed.) Rice blast disease. Wallingford: CAB, 1994. p. 381-408.

PRABHU, A. S.; FARIA, J. C.; CARVALHO, J. R. P. Efeito da brusone sobre a matéria seca, produção de grãos e seus componentes em arroz de sequeiro. Pesquisa Agropecuária Brasileira, Brasília, v. 21, n. 5, p. $495-$ $500,1986$.

PRABHU, A. S.; FILIPPI, M. C.; ZIMMERMMANN, F. J. P. Genetic control of blast in relation to nitrogen fertilization in upland rice. Pesquisa Agropecuária Brasileira, Brasília, v. 31, n. 5, p. 339-347, 1996.

SHANER, G.; FINNEY, R. E. The effect of nitrogen fertilization on the expression of slow mildewing resistance in Knox wheat. Phytopathology, St. Paul, v. 67, n. 8, p. $1051-1056,1977$.

SUN, S. Y.; JIN, M. Z.; ZHANG, Z. M.; TAO, X. L.; TAO, R. X.; FANG, D. F. Rice blast disease and its control. Shangai: Shangai Scientific and Technology, 1986. $182 \mathrm{p}$.

WAQUIL, P. D. O setor de grãos e de oleaginosas no Mercosul. In: VIEIRA, W.; CARVALHO, F. (Ed.).

Mercosul: agronegócios e desenvolvimento econômico. Viçosa, MG: UFV, 1997. p. 177-197. 